\title{
LAYANAN INFORMASI KARIR BERBASIS AJARAN ISLAM UNTUK MENINGKATKAN KEMAMPUAN MEMBUAT KEPUTUSAN KARIR SISWA SMK MUHAMMADIYAH SALAMAN
}

\author{
Hijrah Eko Putro ${ }^{(1)}$, Sugiyadi ${ }^{(2)}$ \\ Program Studi Bimbingan dan Konseling \\ Fakultas Keguruan dan Ilmu Pendidikan \\ Universitas Muhammadiyah Magelang \\ E-mail: hijrah.ummgl@gmail.com
}

\begin{abstract}
Abstrak
Penelitian ini bertujuan untuk mengetahui pelaksanaan layanan informasi karir di SMK Muhammadiyah Salaman, mengetahui kondisi kemampuan membuat keputusan karir siswa, menghasilkan model layanan informasi karir berbasis ajaran islam untuk meningkatkan kemampuan membuat keputusan karir siswa, dan mengetahui efektivitas layanan informasi karir berbasis ajaran islam untuk meningkatkan kemampuan membuat keputusan karir siswa SMK Muhammadiyah Salaman. Populasi penelitian, siswa kelas III SMK Muhammadiyah Salaman sebanyak 9 kelas dengan jumlah 290 siswa diambil sampel 32 siswa. Desain dalam penelitian ini, pre-experimental one group pretestposttest design dengan purposive sampling. Teknik analisis data menggunakan Paired Sample t-Test menggunakan satu variabel bebas. Hasilnya, layanan informasi karir berbasis agama islam efektif untuk meningkatkan kemampuan membuat keputusan karir siswa sebesar $21 \%$ dengan $-t$ hitung $<-t$ tabel yaitu $(-8,148)<\mathrm{t}$ tabel $(-2,040)$.
\end{abstract}

Kata kunci: model bimbingan kelompok, motivasi belajar, teknik role playing

\begin{abstract}
This research purpose to investigate the implementation of information services career in SMK Muhammadiyah Salaman, knowing the condition of the ability to make career decisions of students, resulting in a service model career information based on the teachings of Islam to improve the ability to make career decisions of students, and examine the effectiveness of information services based career teachings of Islam to improve make career decisions of students of SMK Muhammadiyah Salaman. The research population, third grade students of SMK Muhammadiyah Salaman as much as 9 classes with 290 students the number of samples taken 32 students. Designs in this research, pre-experimental one-group pretest-posttest design with a purposive sampling. Analysis using Paired Sample t-Test uses one independent variable. As a result, career information services based Islamic religion effective way to improve students' career decision-making ability by $21 \%$ with $t$ count $<t$ table is $(-8.148)<t$ table $(-2.040)$.

Key words: model of group guidance, motivation to learn, role playing techniques
\end{abstract}

Info Artikel

Diterima Desember 2016, disetujui Desember 2016, diterbitkan Desember 2016 PENDAHULUAN

Dipublikasikan Oleh: Program Studi Bimbingan dan 
Membuat keputusan karir adalah tugas perkembangan penting pada masa remaja akhir dan dewasa awal (Super dalam Lounsbury et al, 2004). Menurut Super \& Crites (Lounsbury et al, 2004) remaja dapat membuat keputusan karir ketika mereka memahami kemampuan (termasuk kecerdasan umum, bakat khusus, prestasi akademik, dan keterampilan kerja), minat kejuruan, dan karakteristik kepribadian yang dimiliki, tetapi kenyataannya tidak demikian, kurangnya motivasi dalam keterlibatan pemiliahan karir, kurang pemahaman diri, kurangnya pemahaman lingkungan, serta kurangnya pemahaman hubungan diri dan lingkungan menyebabkan peserta didik tidak dapat membuat keputusan karir. Untuk memfasilitasi peserta didik agar mampu membuat keputusan karir dibutuhkan suatu layanan yang dapat membantu peserta didik memahami ciri-ciri yang melekat dirinya dan faktor-faktor pekerjaan atau tuntutan kerja yang sesuai dengan dirinya sehingga peserta didik mampu membuat keputusan karir sesuai dengan ciri-ciri yang melekat pada dirinya dan faktor-faktor pekerjaan atau tuntutan kerja yang sesuai dengan dirinya. Layanan yang dimaksud adalah bimbingandan konseling karir.

Permasalahan karir merupakan permasalahan masa depan siswa, sehingga kegiatan sekarang akan sangat mempengaruhi masa depan siswa. Agar siswa SMK dapat menyiapkan masa depannya dengan baik, siswa harus memiliki bekal dengan sejumlah informasi karir yang akan dipilihnya.

$$
\text { Dalam kegiatan layanan }
$$
informasi karir sangat diperlukan suatu pendekatan yang dapat memberikan upaya preventif bagi siswa di masa depannya telah memperoleh suatu keberhasilan atau kesuksesan yang dinginkan, sehingga aspek-aspek yang lain dalam proses perkembangannya tidak terlupakan. Salah satu pendekatanya melalui pendekatan ajaran islam yang seharusnya diimplementasikan dan diintegrasikan dalam kegiatan layanan informasi karir di sekolah karena ajaran islam yang bersumber dari AlQuran dan Al-Hadits merupakan petunjuk bagi manusia yang menjadikan manusia terhindar dari dosa.

Ajaran islam merupakan suatu ajaran yang bersumber pada $\mathrm{Al}$ Quran dan Al Hadits. Pengintegrasian ajaran islam ke dalam kegiatan layanan informasi karir diharapkan memberikan suatu kontribusi yang besar dalam meningkatkan aspirasi karir siswa. Aspirasi karir siswa dapat memberikan daya tarik atau preferensi terhadap pilihan karir atau pekerjaan tertentu, dan aspirasi karir berkembang sebagai penerimaan diri dari orang lain secara signifikan serta potensi seseorang berdasarkan performa akademis.

Mengintegrasikan ajaran islam dalam kegiatan layanan informasi karir adalah satu upaya yang muncul 
dari reaksi terhadap adanya fenomena dari sebuah keberhasilan dan kesuksesan dalam karir seseorang, namun keberhasilan dan kesuksesan tersebut tidak diiringi dengan nilainilai yang terkandung didalam ajaran islam yang bersumber dari Al- Quran dan Al-Hadits sebagai petunjuk bagi manusia. Dengan memegang nilainilai yang terkandung di dalamNya akan menjadikan manusia terhindar dari dosa.

Pengintegrasian antara materi layanan informasi karir dan materi ajaran islam adalah sebuah perpaduan antara ajaran islam ke dalam layanan informasi karir di sekolah, hal ini sebagai upaya dalam meningkatkan aspirasi karir siswa dalam menentukan masa depannya yang sesuai dengan nilai-nilai ajaran islam.

Oleh karena itu dalam upaya meningkatkan membuat keputusan karir dalam area pendidikan di sekolah yang terfokus pada siswa, maka penulis menyusun suatu layanan informasi karir berbasis ajaran islam. Penulis kemas melalui sebuah penelitian berjudul "pengaruh layanan informasi karir berbasis ajaran islam untuk meningkatkan kemampuan membuat keputusan karir siswa di SMK Muhammadiyah Salaman".

\section{METODE PENELITIAN}

Metode dalam penelitian ini adalah quasi eksperimen, dengan rancangan pretest-posttest. Para siswa diukur karakteristik kemampuan membuat keputusan karir dengan menggunakan skala keputusan karir. Seluruh subjek penelitian dimasukkan ke dalam satu kelompok yaitu kelompok eksperimen tanpa kelompok kontrol (One Group Pretest-Posttest Design). Kelompok eksperimen diberi perlakuan berupa Layanan Informasi Karir berbasis Islami. Rancangan pengukuran tersebut dapat dilihat pada Tabel 1. berikut:

Tabel 1.

\section{Rancangan Penelitian}

\begin{tabular}{|c|c|c|c|}
\hline Kelompok & Pretest & Perlakuan & Posttest \\
\hline Eksperimen & $O 1$ & $\mathrm{X}$ & $O 2$ \\
\hline \multicolumn{4}{|l|}{ Keterangan: } \\
\hline : Pretest & & & \\
\hline : Posttest & & & \\
\hline : Perlakuan & & & \\
\hline
\end{tabular}

(Layanan Informasi Karir berbasis Islami)

Dalam penelitian ini, jenis bertujuan dimaksudkan untuk sampel yang digunakan adalah mencapai tujuan tertentu, yaitu untuk purposive sampling (pengambilan meningkatkan kemampuan membuat sampel berdasakan tujuan). Sampel keputusan karir siswa. Subyek 
penelitian ini ditetapkan siswa-siswi kelas XII SMK Muhammadiyah Salaman.

Teknik dan instrumen pengumpulan data menggunakan teknik wawancara, obeservasi, dan skala orientasi masa depan. Teknik pengambilan sampel menggunakan purposive random sampling. Analisis data menggunakan analisis data kualitatif deskriptif untuk pelaksanaan layanan informasi karir, sedangkan untuk analisis data skala menggunakan analisis data kuantitatif dengan menggunakan uji-t.

Setelah semua data terkumpul secara lengkap dan sistematis, maka selanjutnya adalah menganalisis data agar menjadi satu fakta sehingga dapat ditarik kesimpulan atas dasar fakta tersebut dengan menggunakan progam statistik yakni cara-cara ilmiah untuk mengumpulkan, menyajikan, menyusun dan menganalisis data yang berwujud angka. Pada penelitian ini sesuai dengan rumusan permasalahan dan tujuan penelitiannya, maka pengolahan dan analisis datanya menggunakan analisis Paired Sample $t$-Test. Analisis dengan menggunakan Paired Sample t-Test dengan pertimbangan dengan penelitian ini menggunakan satu variabel bebas (independent variable), sedangkan progam statistik yang digunakan dalam analisis data adalah SPSS For Windows Versions 16.0.

\section{HASIL DAN PEMBAHASAN}

Analisis yang dilakukan ini bertujuan untuk membuktikan atau menguji hipotesis yang di kemukakan sebelumnya. Adapun teknis analisis data yang digunakan menggunakan bantuan SPSS versi 16.0 untuk mempermudah hitungan data yang didapatkan. analisis data penelitian tersebut adalah dengan tahapan pengolahan analisis sebagai berikut :

Setelah diperoleh data penelitian baik data pre-test dan post-test, maka langkah selanjutnya adalah melakukan analisis data. Analisis data ingin digunakan untuk menguji hipotesis yang di ajukan sebelumnya. Hasil pengujian hipotesis tersebut, selanjutnya akan digunakan sebagai pembahasan permasalahan yang ada.

Paired Sample T-test adalah uji yang dilakukan terhadap dua sampel yang berpasangan (paired). Sampel yang berpasangan diartikan sebagai sebuah sampel dengan subyek yang sama, namun mengalami dua perlakuan atau pengukuran yang berbeda.

Uji ke efektivan layanan informasi karir untuk meningkatkan kemampuan dalam membuat keputusan karir dengan statistic non parametric melalui uji paired samples T-Test. Adapun perhitungan menggunakan SPSS 16 hasil perhitungan dapat ditunjukan seperti tabel dibawah ini:

Tabel 2.

Hasil Perhitungan Paired Sample T-Test 
Paired Samples Statistics

\begin{tabular}{|ll|r|r|c|c|}
\hline & & & $\begin{array}{c}\text { Std. } \\
\text { Deviati } \\
\text { on }\end{array}$ & $\begin{array}{c}\text { Std. } \\
\text { Error } \\
\text { Mean }\end{array}$ \\
\hline $\begin{array}{ll}\text { Pair } \\
1\end{array}$ & $\begin{array}{l}\text { Sebelum Perlakuan } \\
\text { Layanan Karir Islami } \\
\text { Setelah Perlakuan } \\
\text { Layanan Karir Isla }\end{array}$ & $\begin{aligned} 140.1 \\
9\end{aligned}$ & 32 & 20.208 & 3.572 \\
& 172.4 & 32 & 23.997 & 4.242 \\
\hline
\end{tabular}

Paired Samples Test

\begin{tabular}{|c|c|c|c|c|c|c|c|c|}
\hline & \multicolumn{5}{|c|}{ Paired Differences } & $\mathrm{t}$ & $\mathrm{df}$ & $\begin{array}{l}\text { Sig. } \\
(2- \\
\text { taile } \\
\text { d) }\end{array}$ \\
\hline & \multirow[b]{2}{*}{ Mean } & \multirow{2}{*}{$\begin{array}{c}\text { Std. } \\
\text { Deviati } \\
\text { on }\end{array}$} & \multirow{2}{*}{$\begin{array}{l}\text { Std. } \\
\text { Error } \\
\text { Mean }\end{array}$} & \multicolumn{2}{|c|}{$\begin{array}{c}95 \% \\
\text { Confidence } \\
\text { Interval of } \\
\text { the } \\
\text { Difference }\end{array}$} & & & \\
\hline & & & & Lower & Upper & & & \\
\hline $\begin{array}{ll}\text { Pai } & \text { Sebelum Perlakuan Layanan } \\
\text { r } 1 & \text { Karir Islami - Setelah } \\
& \text { Perlakuan Layanan Karir Isla }\end{array}$ & $\begin{array}{r}- \\
32.21 \\
9\end{array}$ & 22.369 & 3.954 & $\begin{array}{r}- \\
40.28 \\
4\end{array}$ & $\begin{array}{r}- \\
24.15 \\
4\end{array}$ & $\begin{array}{r}8.14 \\
8\end{array}$ & 31 & .000 \\
\hline
\end{tabular}

Berdasarkan hasil perhitungan pada tabel di atas, dapat diketahui bahwa $\mathrm{t}$ hitung $(-8,148)<\mathrm{t}$ tabel $(-$ 2,040), jadi Ho ( Hipotesis Nol ditolak ) sehingga dapat disimpulkan bahwa ada perbedaan skala kemampuan membuat keputusan karir siswa antara sebelum dan sesudah dilaksanakan layanan informasi karir berbasis islami. Dari nilai mean dapat diketahui bahwa rata-rata nilai mean sesudah layanan informasi karir berbasis islami lebih tinggi dari layanan informasi karir berbasis islami,dengan ini dapat disimpulkan bahwa layanan informasi karir berbasis islami dapat meningkatkan kemampuan membuat keputusan karir siswa kelas 3MM1 SMK Muhammadiyah Salaman.

Pengambilan keputusan kedua yaitu berdasarkan signifikansi, dapat diketahui bahwa signifikansi dari tabel sebesar 0,000 lebih kecil dari 0,05 maka Ho ditolak. Kesimpulannya bahwa ada perbedaan skala kemampuan membuat keputusan karir siswa antara sebelum dan sesudah dilaksanakan layanan informasi karir 
berbasis islami, sehingga layanan informasi karir berbasis islami efektif untuk meningkatkan kemampuan membuat keputusan karir siswa SMK Muhammdiyah Salaman.

Untuk dapat menyimpulkan efektif tidaknya pelayanan Informasi yang telah dilakukan terhadap responden, peneliti mendasarkan pada argumen yang dibangun, yakni: Layanan dapat dikatakan efektif jika dominan responden mengalami kenaikan skor kemampuan membuat keputusan karir setelah dilakukan perlakuan.

Dalam hasil analisis terbukti terdapat peningkatan rata-rata kemampuan membuat keputusan karir siswa dalam angket pre-test dan posttest; jadi ada pengaruh layanan Informasi karir berbasis islami untuk meningkatkan kemampuan membuat keputusan karir. Bukti peningkatan kemampuan membuat keputusan karir siswa dapat di lihat dalam tabel skor atau perbandingan antara hasil pre-test dan hasil post-test.

Gambar 1.

Histogram Skala Sebelum Perlakuan

\section{sebelum perlakuan}

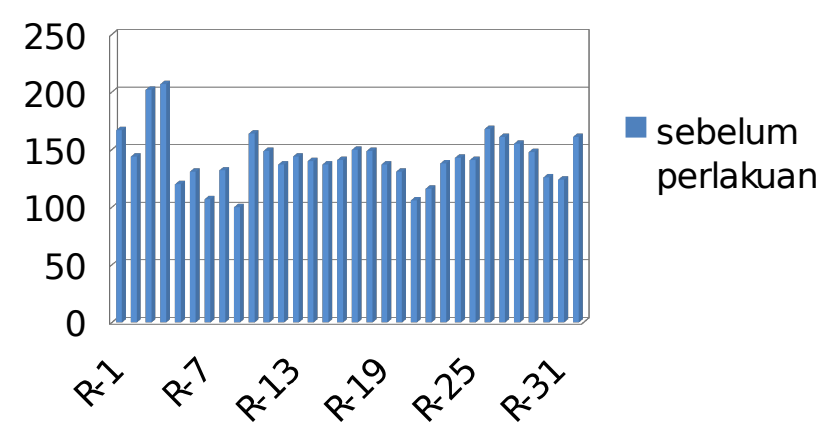


Gambar 2.

Histogram Skala Setelah Perlakuan

\section{skala setelah perlakuan}

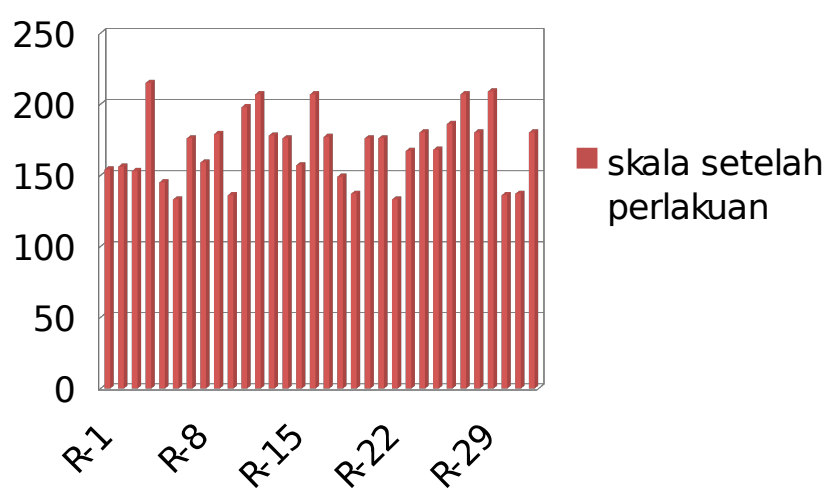

Tabel 4.

Prosentase Perubahan Skala Kemampuan Keputusan Karir

\begin{tabular}{|l|c|c|c|c|c|c|c|c|}
\hline \multirow{2}{*}{ NAMA } & \multicolumn{9}{|c|}{ NILAI } & $\begin{array}{c}\text { PERUBA } \\
\text { HAN }\end{array}$ & $\begin{array}{c}\text { PROSENT } \\
\text { ASE }\end{array}$ \\
\cline { 2 - 10 } & PRETEST & $\mathbf{\%}$ & $\begin{array}{c}\text { KETERANG } \\
\text { AN }\end{array}$ & $\begin{array}{c}\text { POSTE } \\
\text { ST }\end{array}$ & $\mathbf{\%}$ & KETERANGAN & & \\
\hline R-1 & 167 & 70 & TINGGI & 154 & 64 & SEDANG & 13 & -8 \\
\hline R-2 & 144 & 60 & SEDANG & 156 & 65 & SEDANG & 12 & 8 \\
\hline R-3 & 202 & 84 & TINGGI & 153 & 64 & SEDANG & 49 & -32 \\
\hline R-4 & 207 & 86 & $\begin{array}{c}\text { TINGGI } \\
\text { R-5 }\end{array}$ & 215 & 90 & $\begin{array}{c}\text { TANGAT } \\
\text { RINGI }\end{array}$ & 8 & 4 \\
\hline R-6 & 120 & 50 & RENDAH & 145 & 60 & SEDANG & 25 & 21 \\
\hline R-7 & 107 & 45 & RENDAH & 176 & 73 & TINGGI & 69 & 64 \\
\hline R-8 & 132 & 55 & RENDAH & 159 & 66 & SEDANG & 27 & 20 \\
\hline R-9 & 100 & 42 & RENDAH & 179 & 75 & TINGGI & 79 & 79 \\
\hline R-10 & 164 & 57 & SEDANG & 136 & 68 & SEDANG & 28 & -21 \\
\hline R-11 & 149 & 62 & SEDANG & 198 & 83 & TINGGI & 49 & 33 \\
\hline R-12 & 137 & 57 & SEDANG & 207 & 86 & $\begin{array}{c}\text { SANGAT } \\
\text { TINGGI }\end{array}$ & 70 & 51 \\
\hline R-13 & 144 & 60 & SEDANG & 178 & 74 & TINGGI & 34 & 24 \\
\hline R-14 & 140 & 58 & SEDANG & 176 & 73 & TINGGI & 36 & 26 \\
\hline R-15 & 137 & 57 & SEDANG & 157 & 65 & SEDANG & 20 & 15 \\
\hline R-16 & 141 & 59 & SEDANG & 207 & 86 & SANGAT & 66 & 47 \\
\hline R-17 & 150 & 63 & SEDANG & 177 & 74 & TINGGI & 27 & 18 \\
\hline R-18 & 149 & 62 & SEDANG & 149 & 62 & SEDANG & 0 & 0 \\
\hline R-19 & 137 & 57 & SEDANG & 137 & 57 & SEDANG & 0 & 0 \\
\hline
\end{tabular}

Dipublikasikan Oleh: Program Studi Bimbingan dan 


\begin{tabular}{|c|c|c|c|c|c|c|c|c|}
\hline \multirow{2}{*}{ NAMA } & \multicolumn{6}{|c|}{ NILAI } & \multirow[t]{2}{*}{$\begin{array}{l}\text { PERUBA } \\
\text { HAN }\end{array}$} & \multirow[t]{2}{*}{$\begin{array}{c}\text { PROSENT } \\
\text { ASE } \\
\end{array}$} \\
\hline & PRETEST & $\%$ & $\begin{array}{c}\text { KETERANG } \\
\text { AN }\end{array}$ & $\begin{array}{c}\text { POSTE } \\
\text { ST }\end{array}$ & $\%$ & KETERANGAN & & \\
\hline R-20 & 131 & 55 & RENDAH & 176 & 73 & TINGGI & 45 & 34 \\
\hline $\mathrm{R}-21$ & 106 & 44 & RENDAH & 176 & 73 & TINGGI & 70 & 66 \\
\hline $\mathrm{R}-22$ & 116 & 48 & RENDAH & 133 & 55 & SEDANG & 17 & 15 \\
\hline $\mathrm{R}-23$ & 138 & 58 & SEDANG & 167 & 70 & TINGGI & 29 & 21 \\
\hline R-24 & 143 & 60 & SEDANG & 180 & 75 & TINGGI & 37 & 26 \\
\hline R-25 & 141 & 59 & SEDANG & 168 & 70 & TINGGI & 27 & 19 \\
\hline R-26 & 168 & 70 & TINGGI & 186 & 78 & TINGGI & 18 & 11 \\
\hline R-27 & 161 & 67 & SEDANG & 207 & 86 & $\begin{array}{c}\text { SANGAT } \\
\text { TINGGI }\end{array}$ & 46 & 29 \\
\hline $\mathrm{R}-28$ & 155 & 65 & SEDANG & 180 & 75 & TINGGI & 25 & 16 \\
\hline R-29 & 148 & 62 & SEDANG & 209 & 87 & $\begin{array}{c}\text { SANGAT } \\
\text { TINGGI }\end{array}$ & 61 & 41 \\
\hline R-30 & 126 & 53 & RENDAH & 136 & 57 & SEDANG & 10 & 8 \\
\hline R-31 & 124 & 52 & RENDAH & 137 & 57 & SEDANG & 13 & 10 \\
\hline R-32 & 161 & 67 & SEDANG & 180 & 75 & TINGGI & 19 & 12 \\
\hline
\end{tabular}

Dari tabel di atas terlihat bahwa sebanyak 32 siswa mengalami kenaikan kemampuan menentukan keputusan karir, dari rata seluruh responden terlihat bahwa rata-rata siswa mengalami kenaikan kemampuan menentukan keputusan karir $91.4 \%$ dan mengalami penurunan sebesar $\quad 8.6 \%$. Untuk lebih memudahkan membaca hasil analisis disajikan dalam tabel seperti dibawah ini:

Tabel 5.

Hasil Analisis Tentang Kemampuan Keputusan Karir

\begin{tabular}{|l|c|c|}
\hline \multicolumn{1}{|c|}{ Siswa } & Jumlah & prosentase \\
\hline $\begin{array}{l}\text { Jumlah siswa yang mengalami } \\
\text { kenaikan skor }\end{array}$ & 29 & 91.4 \\
\hline $\begin{array}{l}\text { Jumlah siswa yang mengalami } \\
\text { penurunan skor }\end{array}$ & 3 & 8.6 \\
\hline Jumlah & $\mathbf{3 2}$ & $\mathbf{1 0 0 \%}$ \\
\hline
\end{tabular}

Dari presentase kenaikan dan penurunan kemampuan menentukan keputusan karir tersebut terlihat bahwa dominan responden mengalami kecenderungan kenaikan kemampuan menentukan keputusan karir sebanyak
29 dari 32 responden (atau sebesar 91.4\%) setelah mendapatkan layanan informasi karir berbasis islami. Berdasarkan jumlah angka di atas peneliti berani menyimpulkan bahwa perlakuan pelayanan informasi karir 
berbasis islami dapat dikatakan efektif.

\section{KESIMPULAN}

Layanan informasi karir sudah dilaksanakan di SMK Muhammadiyah Salaman sudah terpogram dalam program layanan Informasi. Pelaksanaan layanan informasi karir belum ada yang menggunakan landasan agama Islam sebagai basis pelaksanaan layanan informasi karir untuk meningkatkan kemampuan membuat keputusan karir siswa.

Layanan Informasi Karir merupakan salah satu bentuk layanan yang penting di selenggarakan oleh sekolah. Kegiatan belajar yang dilaksanakan di sekolah, tentru tidak bisa lepas dari adanya kegiatan belajar mengajar dan juga faktor-faktor yang dapat mempengaruhinya terhadap proses belajar mengajar antara lain anak didik, pendidik,pembimbing, kurikulum, metode juga sarana dan prasarana. Dalam penelitian ini penulis mengangkat metode yang digunakan adalah "layanan informasi karir berbasis islami untuk meningkatkan kemampuan membuat keputusan karir siswa kelas 3MM1 ternyata terbukti dengan adanya perubahan atau peningkatan skor mayoritas siswa setelah di laksanakan treatment atau perlakuan Layanan Informasi karir.

Layanan informasi karir berbasis ajaran Islam efektif untuk untuk meningkatkan kemampuan membuat keputusan karir siswa pada semua indikator yang meliputi: monitoring, planning dan evaluation. Simpulan ini didasarkan pada perbedaan skor evaluasi awal dan evaluasi akhir, di mana ada peningkatan tingkat kemampuan membuat keputusan karir siswa sebelum dan sesudah diberi konseling kelompok dengan teknik self regulated learning sebesar $21 \%$. Hasil ini diperkuat melalui uji efektivitas menggunakan t-test yang menunjukan -t hitung $<-t$ tabel yaitu $(-8,148)<(-2,040)$.atau data $\mathrm{Sig}<0,05$ $(0,000)$.

Sehubungan dengan hasil penelitian yang penulis lakukan, kiranya dapat memberikan saran sebagai berikut:

1. Bagi Guru Pembimbing (konselor) a. Dalam merencanakan, menyusun, melaksanakan, mengevaluasi program layanan informasi karir hendaknya tidak hanya berpijak pada logika saja tetapi memperhatikan aspek-aspek ajaran islam (spiritual)

b. Bila layanan informasi karir berbasis ajaran islam ini akan dilaksanakan oleh guru pembimbing, hendaknya selalu berpegang dengan nilai-nilai agama Islam dan memperhatikan prosedur dan etika berkarir.

c. Langkah-langkah dalam meniti karir bagi siswa, hendaknya guru pembimbing memberikan perhatian pada aspek-aspek ajaran islam.

2. Bagi Peneliti selanjutnya 
Penelitian ini diakui masih bersifat tentatif, untuk menjadi layanan yang baku masih diperlukan pakar ahli dan seminar dengan para pengguna di lapangan. Oleh sebab itu kepada para peneliti dan pengguna di masa mendatang disarankan untuk bisa menindaklanjuti hingga menjadi program yang baku dan bisa dimanfaatkan dalam lapangan yang lebih luas.

\section{DAFTAR PUSTAKA}

Abdurrahman. A, dkk, 2008. Pedoman Hidup Islami. Yogyakarta: Suara Muhammadiyah.

Ahmad. 2009. Konsep Bekerja Menurut Pandangan Islam. Jakarta: Institut dakwah dan Latihan Islam. Baheis.

Al-Mundziri. 1996. At-Tarqib wat Tarhib, Tahqiq Ibrahim Syamsudin. Darul Kutub alIlmiah. Beirut.

Al-Sya'rani. A.A : Penyadur, Wikarta. E, 2004. 99 Akhlak Sufi, Meniti Jalan Menuju Surga Bersama Orang-Orang Sufi. Bandung: Al-Bayyan Mizan.

Al-Quranulkarim, 2010. Syaamil AlQuran Miracle The Reference. Kementrian Agama RI : SYGMA.

Barnes, A. 2010. Career Research \& Development. The Jounal of the National Instute for Career
Education and Counseling. 23. 1-36.

Brown, S.D. 2008. Career Information, Career Counseling, and Career Development: Ninth Edition. University of North Carolina at Chapel Hill: Pearson.

dan Lent. R.W. 2005. Career Development and Counseling: Putting theory and research to work. Canada: Wiley.

Bukhori. 2009. Hadits Shahih Bukhori. Surabaya: Gita Media Press.

Cobb, R.A, McIntire, W.G, dan Pratt, P.A. 1989. Vocational and Educations of High School Students: A Problem for Rural America. Research in Rural Education. 6/2. University of Maine.

Danziger, N dan Eden, Y. 2006. Student Career Aspirations and Perceptions: The Case of Israeli Accounting Students. Accounting Education: an International Journal 15/2, The College of Management, Academic Studies, Israel.

Dawwabah, A.M. 2009. Menjadi Entrepreneur Muslim Tahan Banting. Surakarta : Al Jadid.

Faridl. M. 2001. Panduan Hidup Muslim. Bandung : Pustaka.

Faqih, A.R. 2001. Bimbingan dan Konseling dalam Islam. Yogyakarta: UII Press. 
Flurentin, E. 1991. Organisasi dan Administrasi Bimbingan di Sekolah. Malang: POPF IKIP Malang.

Hidayat. R. 2004. Etos Kerja dalam Pandangan Islam Untuk Menjadi Sumber Daya Manusia Yang Kreatif. Jurnal Kajian Bisnis. Vol.13/3:79-83.

Rais, D, dkk. 2005. Pedoman Hidup Islami. Yogyakarta: P3SI.

Roos, L. 2006. National impact: the effects of carreer development on employment among juvenile offenders. National Forum of Education Administration and Supervision Journal, 23/4,1-8. Pralrie View A\&M University.
Slameto. 2003. Belajar dan Faktorfaktor yang Mempengaruhinya. Jakarta: Rineka Cipta.

Walgito. B. 2004. Bimbingan dan Konseling : Studi \& Karir. Yogyakarta: Andi Offset.

Wall, J, Covell, K, dan Macintyre, P.D. 1999. Implications of Social Support for Adolescents.

Yafi'e. A. 2000. Etos Kerja Umat Islam. Jakarta: Pustaka Intermasa.

Yusuf, S. dan Nurihsan, A.J. 2009. Landasan Bimbingan \& Konseling. Bandung: Remaja Rosdakarya. 